\title{
Model of the Ultimate Stress State of the Coated Tool Cutter Material
}

\author{
Aleksei Osinnii ${ }^{1, *}$, Jury Bublikov², Anatoli Chigarev ${ }^{3}$, Anna Okun’kova ${ }^{1}$, Nataliya Kapustina ${ }^{1}$ \\ ${ }^{1}$ Moscow State Technological University "STANKIN", RU-127055, Moscow, Russia. \\ ${ }^{2}$ IDTI RAS, Moscow, Russia. \\ ${ }^{3}$ Belarusian State University, BL-220030, Minsk, Belarus.
}

\begin{abstract}
The article proposes a model of the ultimate stress state of the material of the coated tool cutter. It is found that with an increase in the fracture toughness of a tool in connection with the material ductility the machining accuracy deteriorates due to arising elastic-plastic vibrations of the tool cutter. In case when no ultimate stress state is reached, that is, a tool operates in the elastic region, then an alternating stress distribution diagram is realized for the tool cutter at the beam approximation. Therefore, in addition to the frictional vibrations, arising from the interaction between the tool cutter and a workpiece, the elastic vibrations can arise, which affects the machining accuracy and the service life of the coated tool cutter. The use of coatings makes it possible not only to increase the wear resistance of cutting tools, but also to transform the stress distribution diagrams of the normal $\sigma_{N}$ and tangential $\tau_{\gamma}$ contact stresses acting on the rake face of the cutting tool. In particular, it is possible to control the length of the total contact area between the chips and the tool rake face.
\end{abstract}

\section{Introduction}

The study of the ultimate stress state of a tool cutter is an important task aimed at predicting the service life of a coated tool cutter and its fracture pattern [1]. The deposition of wear-resistant coatings is one of the prevailing methods for improving the performance properties of cutting tools [2, 3]. Accordingly, the predictive modeling of the cutting properties of coated tools is an important scientific and practical challenge. Various approaches are being used to find a solution to the above challenge. In particular, the method of finite element model (FEM) is being increasingly used [4-12], as well as the shear-lag model [13] and the discrete element method (DEM) [14]. The number of other methods includes the Bower and Fleck's equation and the Hamilton's equation [15] and the microcrack formation theory [16]. In $[17,18]$, the studies were focused on the application of the methods based on the linear elastic fracture mechanics (LEFM). The issues concerning the influence of various coating defects (in particular, microdroplets) on the general working efficiency of a cutting tool were considered separately [19-24]. The probabilistic methods that take into account the stochastic nature of the deposition process are often used to simulate the process of deposition of coatings on metal-cutting tools [25-31]. Moreover, the cutting process is also a stochastic process that requires an appropriate approach during the modeling. In recent years, the wear-resistant coatings with new compositions and architectures are being actively developed. In particular, the multilayered coatings are being widely used due to their contribution to the additional significant improvement in the working efficiency of the metal-cutting tools [32-37]. At the same time, the methods of coating deposition are being improved to control the properties of the coatings by creating the systems of complex composition and architecture [3847]. The wear-resistant coatings of new generation are able to change significantly the cutting conditions, and this fact should be taken into account during the modeling of the state of a tool cutter [48-70]. The aim of this study is to create a model of the ultimate stress state of the material of the coated tool cutter, taking into account the stochastic nature of loading during the cutting process and the effect of the multilayered wearresistant coatings of new generation.

\section{Developing a model for the ultimate stress state of the material of coated tool cutter}

Let us consider the stress state of the tool cutter in the plane of the rake face (Fig. 1): the plane of $B X Y$, which is affected by the average contact specific loads that create the distributed pressure $P$, demonstrates a diagram shown in Fig. 1 b.

Then, in the plane of $B X Y$, a plane stress state is realized in the quadrangle of $B A C E$. Here, the region of $A R B$ means an absolutely rigid body, that is, a region without plasticity. In fact, this region has linear 
elasticity, and in order to simplify the model, it will be assumed to be the $A R B$. In case when the ultimate stress state is reached, the stresses of $\sigma_{x}, \sigma_{y}, \tau_{x y}$ will satisfy the equations of quasi-static equilibrium.

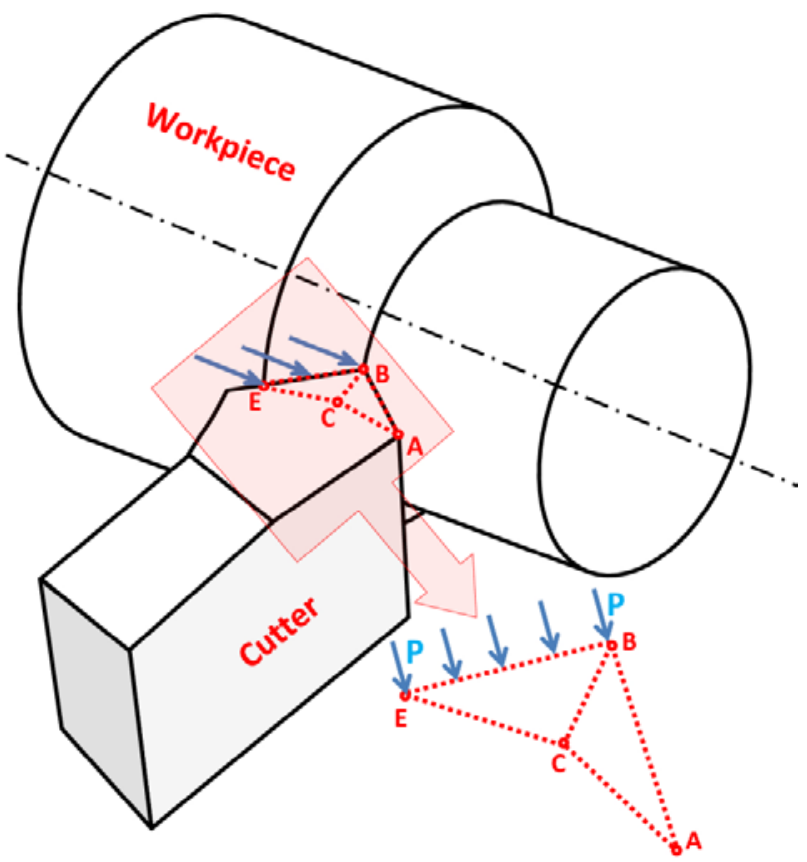

(a)

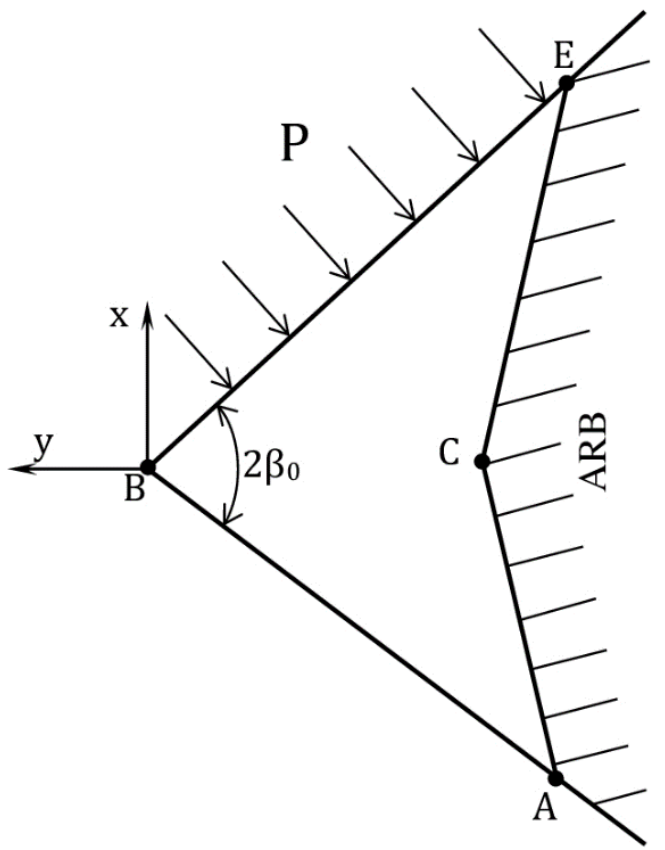

(b)

Fig. 1. Location of the region under consideration: (a) based on the cutting pattern and (b) in the plane of $B X Y$, in which the pressure $P$ is distributed. $A R B$ is the absolutely rigid body, the angle $2 \beta_{0}=\varepsilon$ (apex angle).

$$
\begin{aligned}
& \frac{\partial \sigma_{x}}{\partial x}+\frac{\partial \tau_{x y}}{\partial y}=0 \\
& \frac{\partial \tau_{x y}}{\partial x}+\frac{\partial \sigma_{y}}{\partial y}=0
\end{aligned}
$$

and the condition of ductility:

$$
\left(\sigma_{x}-\sigma_{y}\right)^{2}+4 \tau_{x y}^{2}=4 k^{2}
$$

The rates of plastic deformations determined by the relationships are as follows:

$$
\begin{gathered}
\varepsilon_{x}=\frac{\partial v_{x}}{\partial x}, \varepsilon_{y}=\frac{\partial v_{y}}{\partial y}, \\
\varepsilon_{x y}=\frac{\partial v_{x}}{\partial y}+\frac{\partial v_{y}}{\partial x}, \\
v_{x}=\frac{\partial u}{\partial t}, v_{y}=\frac{\partial v}{\partial t}
\end{gathered}
$$

where $u, v$ are the displacements along the $x, y$ axis.

The conditions for isotropy of the plastic state and incompressibility of the material are as follows, respectively:

$$
\begin{gathered}
\frac{\varepsilon_{x}-\varepsilon_{y}}{\sigma_{x}-\sigma_{y}}=\frac{\varepsilon_{x y}}{\tau_{x y}}=\lambda \geq 0 \\
\varepsilon_{x}+\varepsilon_{y}=0
\end{gathered}
$$

The solution to the problem in Cartesian coordinates $x, y$ can be simplified by taking the coordinates $\alpha, \beta$, when the coordinate lines are directed along the lines of the maximum displacements, that is, along the slip curves. As is known, a slip curve is a line, each point of which touches the area of the maximum tangential stress. In the coordinates $\alpha, \beta$, the relationships for the rates of deformation are simplified (Fig. 2).

$$
\varepsilon_{\alpha}=\varepsilon_{\beta}=0, \varepsilon_{\alpha \beta} \geq 0
$$

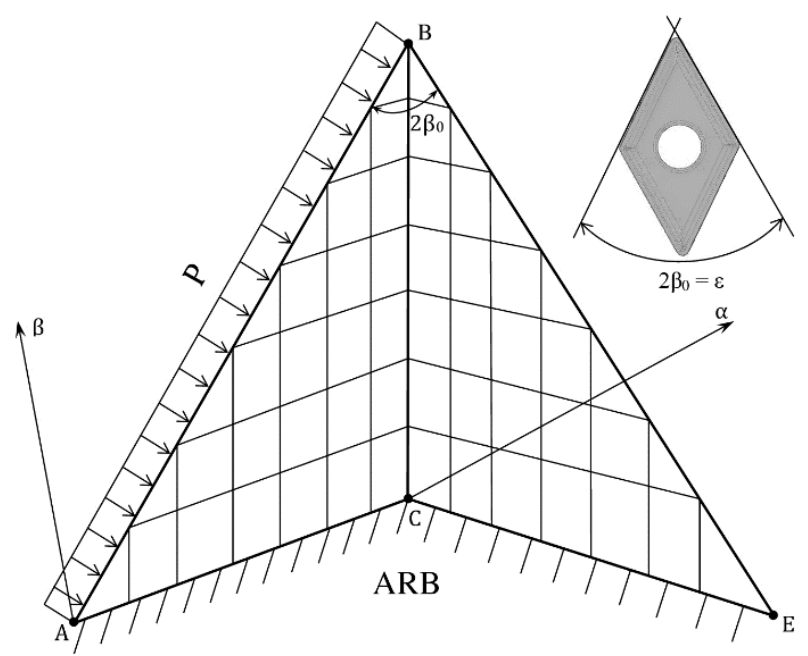

Fig. 2. Field of material slip curves in the region of plastic deformation of the cutting wedge of the tool, when $\varepsilon=2 \beta_{0} \leq$ $\pi / 2$.

Figure 2 exhibits the field of material slip curves in the region of plastic deformation of the tool, for the case when $\beta_{0} \leq \pi / 4$, when the stress fields in the area of $A B C$ with the loaded boundary of $A B$ and in the area of $C B E$ with the free boundary of $B E$ are uniform, but different, and, therefore, the stresses on the line of $B C$ are 
discontinuous. In case when $\beta_{0} \leq \pi / 4$, the grid of slip curves has the shape depicted in Fig. 3.

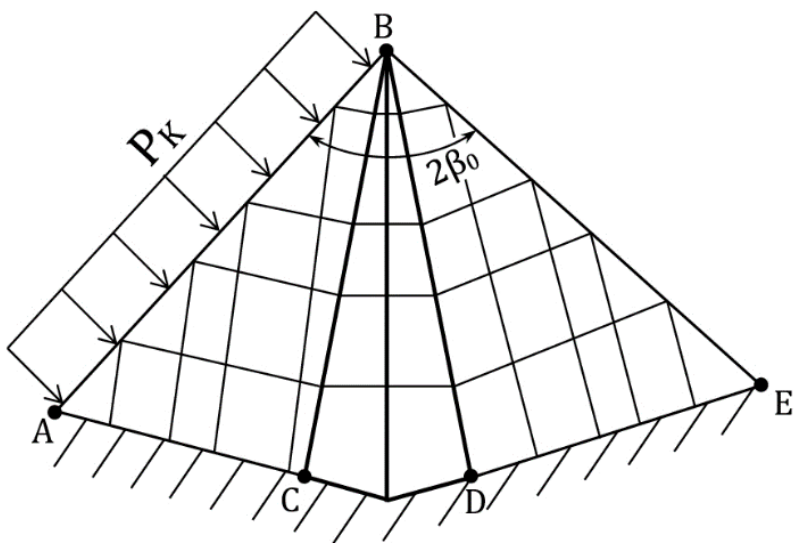

Fig. 3. Grid of slip curves, when $\beta_{0} \leq \pi / 2$.

The ultimate pressure, corresponding to the field of slip curves and the continuous stress field in Fig. 3, can be calculated as follows:

$$
P_{K}=2 k\left[1+\left(2 \beta_{0}-\frac{\pi}{2}\right)\right]
$$

When the area of the angle, where the slip curves form a fan-shaped pattern, tends to zero, we get the slip curve geometry in Fig. 3, which realization requires the ultimate pressure equal to:

$$
P_{K}^{(1)}=2 k\left[1+\sin \left(2 \beta_{0}-\frac{\pi}{2}\right)\right]
$$

It should be noted that this solution also satisfies all the conditions for the stresses when $\beta_{0} \geq \pi / 4$, if the grid of slip curves looks like depicted in Fig. 4.

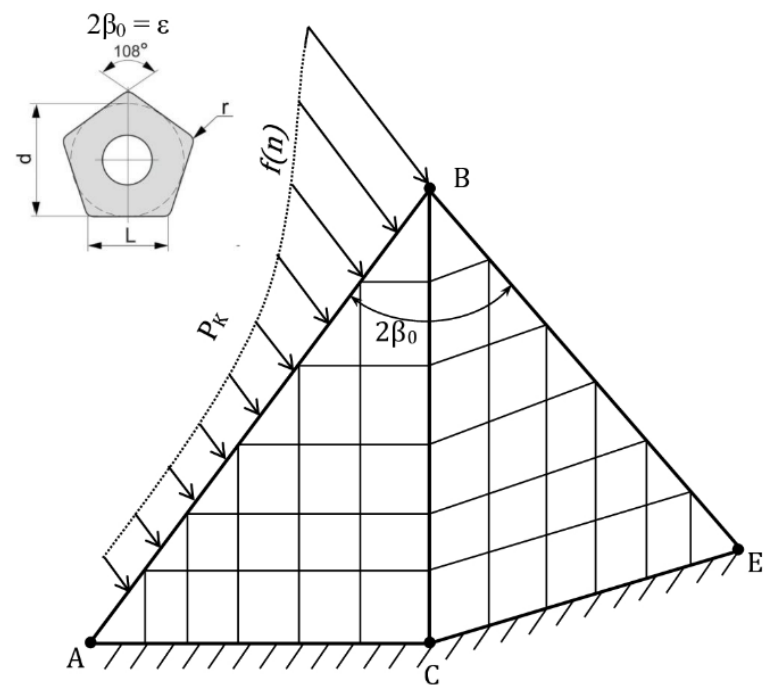

Fig. 4. Grid of slip lines, when $\varepsilon=2 \beta_{0} \geq \pi / 2$.

Let us now consider fields of the plastic flow velocities in accordance with the field of slip curves depicted in Fig. 4 . For the coordinates $\alpha$, $\beta$, the boundary of $A B$ is set by the equation of $\alpha=\beta=\eta$. Then the plastic deformation rate for the boundary of $A B$ in a normal plane is $f(\eta)$. Let us denote the velocity components in the directions of $\alpha_{1}, \beta$ as $u, v$, respectively, then at the discontinuity line of $B C$ the velocities are equal to zero. The conditions (6) are as follows:

$$
\frac{\partial u}{\partial \alpha}=\frac{\partial v}{\partial \beta}=0
$$

The solutions (9) will be written as:

$$
u=u(\beta), v=v(\alpha)
$$

Taking into account (1), it is possible to build the field of the plastic flow velocities for the area of $A B C$. For simplicity, let us assume that $A C=1$ (Fig. 5).

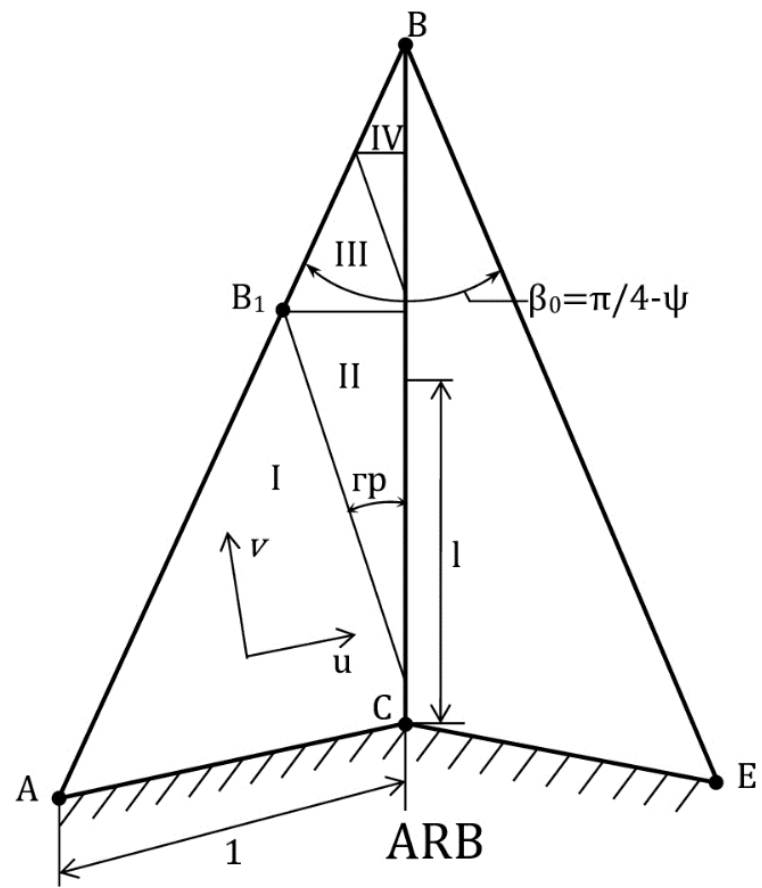

Fig. 5. Field of plastic flow velocities for the area of $A B C$ at $A C=1$.

At the boundary of AC of the plastic zone at the ARB, $v=0$ and thus $v=0$ in the area $I A C B_{1}$. The solution can be written as

$$
v_{I}=0
$$

The directions of $\alpha, \beta$ are inclined at the angle $\pi / \eta$ to $A B$, and the boundary velocities at $A B$ are expressed analytically in the following form:

$$
f(\eta)=u(\eta)-v(\eta)
$$

While constructing the solutions for velocities, the equations (12) are usually required to determine $u(\beta)$ in the region, in which $v$ is already known, for example, in the area $I$ under consideration. The equation (12) can be written as follows:

$$
u(\beta)=\sqrt{2} f(\beta)+v(\beta)
$$

While considering the section of the $A B$ border in the area $I$ from the equation (13), let us define $u(\beta)$ along this border to be used on the boundary of the areas $I$ and II, and we get: 


$$
u_{I}=u_{I I}=\sqrt{2} f(\beta)
$$

Based on the condition at the discontinuity boundary of $B C$, it can be found that the velocity components in the direction of $C B$ will be equal to zero, which can be written as follows:

$$
u \sin \psi+v \cos \psi=0
$$

where $\psi$ is the angle between the direction of $C B$ and the increasing direction of $\beta$.

The equation of the $B C$ line is:

$$
\beta=\frac{\alpha-1}{\tan \psi}
$$

Taking into account (16), the condition (15) is as follows:

$$
v(\alpha)=-t u\left(\frac{\alpha-1}{t}\right), t=\tan \psi
$$

By applying the equation (17) to the section of $B C$ in the area II, we get:

$$
v_{I I}=v_{I I I}=-t \sqrt{2} f\left(\frac{\alpha-1}{t}\right)
$$

When continuing this process using the equations (13) and (17), we get solutions in the form of the following series:

$$
\begin{gathered}
u=\sqrt{2} f(\beta)-t\left[\sqrt{2} f\left(\frac{\beta-1}{t}\right)-t\left\{\sqrt{2} f \frac{\beta-1 / t-1}{t}-\cdots\right\}\right] \\
v=-t\left[\sqrt{2} f\left(\frac{\alpha-1}{t}\right)-t\left\{\sqrt{2} f \frac{\alpha-1 / t-1}{t}-\cdots\right\}\right]
\end{gathered}
$$

At the point $B$, it follows from the equation (19) that:

$$
\begin{gathered}
u=\sqrt{2} f_{B} \sum_{i=0}^{\infty}(-1)^{i} t^{i}=\frac{\sqrt{2} f_{B}}{1+t} \\
v=-\sqrt{2} f_{B} \sum_{i=1}^{\infty}(-1)^{i+1} t^{i}=-\frac{\sqrt{2} f_{B} t}{1+t}
\end{gathered}
$$

By introducing $t=\tan \psi$ into (20) and given that $\frac{\sqrt{2}}{(1+t) \cos \psi}=\frac{1}{\cos \left(\frac{\pi}{n}-\psi\right)}=\frac{1}{\cos \beta}$ we get that the limit of the velocity component at the point $B$ will be equal to zero for the velocity component, parallel to $B C$ and $f_{B} / \cos \beta_{0}$ for the velocity component, not perpendicular to $B$. Therefore, the plastic flow velocity in the plastic region defines the velocity of the elastic line of $B C$ in the point $B$, which is determined uniquely from the condition for the plastic flow velocity on $B C$ and finds the component of the plastic flow velocity at the point $B$, normal to $A B$.

Due to the symmetry, it is clear that the plastic flow velocity field, obtained for the area of $\mathrm{ABC}$, can be also applied to the area of $\mathrm{CDE}$, thus finding the distribution to $\mathrm{EB}$, similar to the distribution of normal velocity to $\mathrm{AB}$.

Before the solution may be distributed, it is necessary to check that the constraints on $f(\eta)$ under the condition of $\varepsilon_{\alpha \beta} \geq 0$ satisfy the equation (6) so that the plastic flow velocity field corresponds to the stress field.
The mechanical interpretation concerning the discontinuity line of $B C$ can be obtained from the concept of the elastic-plastic beam deformation. In the given case, the area of $A B C$ can be considered as a beam of variable cross-section, embedded along $A C E$ and loaded along $A B$ by a uniformly distributed load. This model is well suited for small values of $\beta_{0}$.

For simplicity, let us assume that the area of $A B C$ is rectangular, then the stress distribution diagram in the elastic state looks like $\boldsymbol{a}$ (Fig. 6), $\boldsymbol{b}$ - in elastic-plastic state, or $\boldsymbol{c}$ - when some of the areas are in the plastic state.
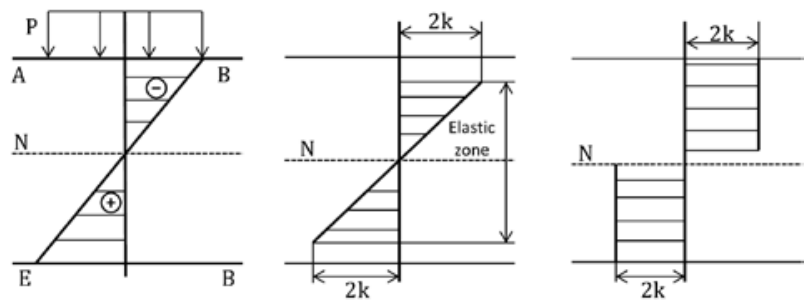

Fig. 6. Stress distribution diagrams in the elastic state.

The neutral line is a line of discontinuity in the plastic stresses. The relationship between the velocity $f(\eta)$ and $\eta$ looks as follows:

$$
\begin{gathered}
f(\eta)=\frac{1}{\sqrt{2}} \varphi\left(\frac{\eta}{\cos \psi}\right) \cos \psi+\varphi\left(\frac{\eta-1}{\sin \psi}\right) \sin \psi H(\eta-1) \\
u=\varphi\left(\frac{\beta}{\cos \psi}\right) \cos \psi, v=-\varphi\left(\frac{\alpha-1}{\sin \psi}\right) \sin \varphi \\
\varepsilon_{\alpha \beta}=\varphi^{\prime}\left(\frac{\beta}{\cos \psi}\right)-\varphi^{\prime}\left(\frac{\alpha-1}{\sin \psi}\right) \\
\varphi(v)=0, \varphi^{\prime}(\ell) \geq 0
\end{gathered}
$$

In case of a tool with the angle of the $\frac{\pi}{2}$ line, the field of plastic deformations and deformation rates increases towards the cutting edge. The stresses change the sign when crossing the neutral line.

\section{Conclusions}

Thus, with an increase in the fracture toughness of a tool through the material ductility the machining accuracy deteriorates due to the arising elastic-plastic vibrations of the tool cutter. When no ultimate stress state is reached, that is, a cutting tool operates in the elastic region, then, according to Fig. 6, an alternating stress distribution diagram is realized for the tool cutter at the beam approximation. Therefore, in addition to the frictional vibrations, arising from the interaction between the tool cutter and a workpiece, the elastic vibrations may occur, which affects the machining accuracy and the service life of the tool cutter. Due to the application of a multilayered structure of the coatings, the above phenomena can be leveled. The use of coatings makes it possible not only to increase the wear resistance of cutting tools, but also to transform the stress distribution diagrams of the normal $\sigma_{\mathrm{N}}$ and tangential $\tau_{\gamma}$ contact stresses acting on the rake face of the cutting tool. In particular, it is possible to control the length of the total 
contact area between the chips and the tool rake face. Due to the above, it is possible to achieve a decrease in the $\sigma_{\mathrm{N}}$ and $\tau_{\gamma}$ contact stresses, improve the heat removal from the cutting zone, increase the thermal conductivity of the surface layers of the tool (the length of the plastic contact $\mathrm{C}_{\gamma \mathrm{P}}$ increases), which, in turn, reduces the specific thermomechanical loads on the cutting edge.

\section{Acknowledgments}

This research was funded by Ministry of Science and Higher Education of the Russian Federation, Grant No. 0707-2020-0025. This work was carried out using equipment provided by the Center of Collective Use of MSUT "STANKIN".

\section{References}

1. V. Astakhov, J. Davim, Tools (Geometry and Material) and Tool Wear (Machining. Springer, 2008)

2. A.A. Vereschaka, S.N. Grigoriev, N.N. Sitnikov, A.D. Batako, Wear, 390-391, 209, (2017)

3. A. Vereschaka, V. Tabakov, S. Grigoriev, N. Sitnikov, G. Oganyan, N. Andreev, F. Milovich, Wear, 420-421, 17-37, (2019)

4. P. Bansal, P.H. Shipway, S.B. Leen, Surf.Coat. Technol., 200(18-19), 5318, (2006)

5. M. Bäker, Comput. Mater, Sci., 64, 79, (2012)

6. Z. Xia, W.A. Curtin, B.W. Sheldon, Acta Mater, 52, 3507, (2004)

7. J.H. Lee, Y.F. Gao, K.E. Johanns, G.M. Pharr, Acta Mater, 60, 5448, (2012)

8. H.C. Hyun, F. Rickhey, J.H. Lee, M. Kim, H. Lee, Eng. Fract. Mech., 134, 304, 2015)

9. K. Holmberg, A. Laukkanen, H. Ronkainen, K. TribolInt, 38, 1035, (2005)

10. T.L. Anderson, Fracture Mechanics: Fundamentals and Applications (CRC Press, Boca Raton, 1994)

11. K. Holmberg, A. Laukkanen, E. Turunen, T. Laitinen, Surf.Coat. Technol., 247, 1-13, (2014)

12. A.L. Mohd Tobi, P.H. Shipway, S.B. Leen, Tribol Int, 58, 29, (2013)

13. K. Wang, F. Zhang, R.K. Bordia, Materials, 11(4), 497, (2018)

14. N. Ferguen, Y. Mebdoua-Lahmar, H. Lahmar, W. Leclerc, M. Guessasma. Surf. Coat. Technol., 371, 287, (2019)

15. M. Białas, Surf. Coat. Technol., 202(24), 6002, (2008)

16. Y. Gu, K. Chen, R. Liu, M.X. Yao, R. Collier, Surf. Coat. Technol., 309, 536, (2017)

17. X.-F. Wu, R.A. Jenson, Int. J. Eng. Sci., 49(3), 279, (2011)

18. X.-F. Wu, R.A. Jenson, Y. Zhao, Mech. Mater., 69(1), 195, (2014)
19. E. Harry, M. Ignat, Y. Pauleau, A. Rouzaud, P. Juliet. Surf. Coat. Technol., 125, 185, (2000)

20. L. Aihua, D. Jianxin, C. Haibing, C. Yangyang, Z. Jun. Int. J. Refract. Hard. Met., 31, 82, (2012)

21. A. Vereschaka, V. Tabakov, S. Grigoriev, N. Sitnikov, F. Milovich, N. Andreev, J. Bublikov, Wear, 438, 203069, (2019)

22. A. Vereschaka, S. Grigoriev, N. Sitnikov, F. Milovich, A. Aksenenko, N. Andreev, Int. J. Adv. Manuf. Technol., 102(9-12), 2953, (2019)

23. V. Alexey, Key. Eng. Mater., 581, 62, (2014)

24. M. Antonov, I. Hussainova, F. Sergejev, P. Kulu, A. Gregor, Wear, 267, 898, (2009)

25. M. Grujicic, S.G. Lai, J. Mater. Sci., 36(12), 2937, (2001)

26. C.K. Birdsall, PIC-MCC., IEEE Trans. Plasma Sci., 19(2), 65, (1991)

27. D.T.K. Kwok, C. Cornet, IEEE Trans. Plasma Sci., 34, 2434, (2006)

28. E. Bultinck, A. Bogaerts, New J. Phys., 11, 103010 , (2009)

29. M. Siemers, A. Pflug, T. Melzig, K. Gehrke, A. Weimar, B. Szyszka, Surf. Coat. Technol., 241, 50, (2014)

30. H. Cansizoglu, M. Yurukcu, M.F. Cansizoglu, T. Karabacak, Thin Solid Films, 583(1), 122, (2015)

31. S. Kumar, W.A. Curtin, Materials Today, 10(9), 34, (2007)

32. G. Skordaris, K.-D. Bouzakis, P. Charalampous, Surf. Coat. Technol., 265, 53, (2015)

33. B.D. Beake, L. Ning, Ch. Gey, S.C. Veldhuis, A. Komarov, A. Weaver, M. Khanna, G.S. FoxRabinovich, Surf. Coat. Technol., 279, 118, (2015)

34. L. Ning, S.C. Veldhuis, K. Yamamoto, Int. J. Mach. Tools Manuf., 48, 656, (2008)

35. A. Vereschaka, V. Tabakov, S. Grigoriev, A. Aksenenko, N. Sitnikov, G. Oganyan, A. Seleznev, S. Shevchenko, Surf. Coat. Technol., 357, 218, 2019)

36. A. Vereschaka, V. Tabakov, S. Grigoriev, N. Sitnikov, N. Andreev, F. Milovich, Wear, 416, 772, (2018)

37. B.D. Beake, G.S. Fox-Rabinovich, Surf. Coat. Technol., 255, 102, (2014)

38. S.N. Grigoriev, M.A. Volosova, A.A. Vereschaka, N.N. Sitnikov, F. Milovich, J.I. Bublikov, S.V. Fyodorov, A.E. Seleznev, Ceram. Int., 46(11), 1824, (2020)

39. W. Kalss, A. Reiter, V. Derflinger, C. Gey, J.L. Endrino, Int. J. Refractory Met. Hard Mater., 24(5), 399, (2006)

40. K. Bobzin, CIRP J. Manuf. Sci. Technol., 18, 1, (2017)

41. A.A. Vereshchaka, A.S. Vereshchaka, O. Mgaloblishvili, M.N. Morgan, A.D. Batako, Int. J. Adv. Manuf. Tech., 72(1-4), 303, (2014) 
42. S. Grigoriev, Y. Melnik, A. Metel, Surf. Coat. Technol., 156(1-3), 44, (2002)

43. O.V. Sobol', A.A. Andreev, S.N. Grigoriev, V.A. Stolbovoy, Probl. At. Sci. Technol., 4, 174, (2011)

44. V.V. Kuzin, S.N. Grigor'ev, M.A. Volosova, Refract. Ind. Ceram., 54, 376, (2014)

45. V.V. Kuzin, S.N. Grigoriev, M.Yu. Fedorov, J. Frict Wear, 36(1), 40, (2015)

46. A.S. Metel, S.N. Grigoriev, Yu.A. Melnik, V.P. Bolbukov, Instrum. Exp. Tech., 55(1), 122, (2012)

47. A.S. Vereschaka, S.N. Grigoriev, V.P. Tabakov, E.S. Sotova, A.A. Vereschaka, M.Y. Kulikov, Key Eng. Mater., 581, 68, (2014)

48. S.N. Grigoriev, O.V. Sobol, V.M. Beresnev, I.V. Serdyuk, A.D. Pogrebnyak, D.A. Kolesnikov, U.S. Nemchenko, J. Frict. Wear, 35(5), 359, (2014)

49. A. Metel, V. Bolbukov, M. Volosova, S. Grigoriev, Y. Melnik, Surf. Coat. Technol., 225, 34, (2013)

50. A.S. Vereschaka, S.N. Grigoriev, E.S. Sotova, A.A. Vereschaka, Adv Mat Res, 712-715, 391, (2013)

51. A.A. Vereschaka, A.S. Vereschaka, S.N. Grigoriev, A.K. Kirillov, O. Khaustova, Procedia CIRP, 7, 311, (2013)

52. A.A. Vereschaka, S.N. Grigoriev, N.N. Sitnikov, G.V. Oganyan, A. Batako, Surf.Coat. Technol., 332, 198, (2017)

53. M.A. Volosova, S.N. Grigor'ev, V.V. Kuzin, Refract Ind Ceram, 56, 91, (2015)

54. A. Vereschaka, V. Tabakov, S. Grigoriev, N. Sitnikov, F. Milovich, N. Andreev, C. Sotova, N. Kutina, Surf. Coat. Technol., 385, 125402, (2020)

55. 55. A. Vereschaka, A. Aksenenko, N. Sitnikov, M. Migranov, S. Shevchenko, C. Sotova, A. Batako, N. Andreev, Tribol. Int. 128, 313 (2018)

56. 56. V. Alexey, Adv Mat Res, 712-715, 347, (2013)

57. 57. J. Gradišek, I. Grabec, S. Siegert, R. Friedrich, Mech Syst Signal Process, 16(5), 831, (2002)

58. 58. A. Vereschaka, M. Volosova, A. Chigarev, N. Sitnikov, A. Ashmarin, C. Sotova, J. Bublikov, D. Lytkin, Coatings, 10(1), 63, (2020)

59. 59. S. Grigoriev, A. Vereschaka, F. Milovich, V. Tabakov, N. Sitnikov, N. Andreev, T. Sviridova, J. Bublikov, Surf. Coat. Technol., 401, 126258, (2020)

60. M.A. Volosova, S.N. Grigor'ev, V.V. Kuzin, Refract. Ind. Ceram., 55, 565, (2015)

61. M. Volosova, S. Grigoriev, A.Metel, A. Shein, Coatings, 8, 287, (2018)

62. M.A. Volosova, S.N. Grigor'ev, V.V. Kuzin, Refract. Ind. Ceram., 56, 197, (2015)

63. M.A. Volosova, S.N. Grigor'ev, V.V. Kuzin, Refract. Ind. Ceram., 55, 487, (2015)
64. V.V. Kuzin, S.N. Grigoriev, M.A. Volosova, J. Frict. Wear, 35, 505, (2014)

65. M.A. Volosova, S.N. Grigoriev, E.A. Ostrikov, Mech. Ind., 17, 720, (2016)

66. Kunarev, E.A., Makarova, T.A., Lyubomudrov, S.A., Russ. Eng. Res., 41(2), 175, (2021)

67. Meurer, M., Augspurger, T., Tekkaya, B., Lima, A.P., Bergs, T. Procedia CIRP, 87, 444 (2020)

68. Ma, W., Shuang, F. Int. J. Adv. Manuf. Technol., 105(5-6), 1933 (2019)

69. Komvopoulos, K., Erpenbeck, S.A. Journal of engineering for industry, 113(3), 253 (1991)

70. Xie, L.-J., Schmidt, J., Schmidt, C., Biesinger, F. Wear, 258(10), 1479 (2005) 